Evidence from animals and humans now provides confirmation that behavioural changes may be seen even at low doses of alcohol consumption.

Ikonomidou et al report that exposure of the rat brain to ethanol for a period of hours during a specific developmental stage induces an apoptotic neurodegenerative reaction that deletes large neurones from several developing sites. ${ }^{7}$ Charness et al report that cell adhesion molecules are inhibited even at exposure to low concentrations of ethanol. These have subsequent effects on neuronal migration, fasciculation, and synaptogenesis, all vital to the developing brain. ${ }^{8}$

Sood et al report a prospective study of 501 motherchild dyads in which the child's behaviour was adversely affected even at low levels of alcohol consumption-as low as one drink per week. They further report that a dose-response relation existed between the level of alcohol consumed and behaviours seen. Children exposed to any level of alcohol, compared with those not exposed, showed 3.2 times greater odds of delinquent behaviour. These relations continued even after other factors were controlled for. ${ }^{9}$ Knupfer et al argue that because of methodological problems, such as differing classifications of drinking practice and the imprecise definition of what low level consumption meant in early studies, more research is needed before conclusive evidence is available about the dose-response relation. ${ }^{10}$

Evidence is currently emerging, but is as yet inconclusive, about the exact dose of alcohol that is safe in pregnancy. The likelihood is that individual differences in alcohol metabolism may protect most women when drinking small quantities. Currently we cannot predict who is and is not at risk.

A small unpublished study carried out by one of the authors (MAS) at St George's Hospital in London showed that just under $50 \%$ of those attending the teenage antenatal clinic drank more than four units on a single occasion and $27 \%$ occasionally got drunk. A further $25 \%$ drank at least once a week. Kaskutas and Graves studied alcohol consumption in 321 pregnant women. They found that when self selecting drinks, the size of the drinks was up to $307 \%$ greater than standard measures. The authors concluded that risk based on current assumptions might actually be much higher than previously expected. ${ }^{11}$

Unlike the position of the department of health-that one to two units a week in pregnancy are safe - the position adopted increasingly in other countries is that no level of alcohol consumption is known to be safe in pregnancy. A health promotion message about a safe amount of alcohol, although designed to protect the pregnant mother and the developing child, can be dangerous as it can be so easily misinterpreted. The uncertain level of individual risk to the developing fetus together with the possibility of misinterpreting a health promotion message mean that the only safe message in pregnancy is abstinence from alcohol.

Raja A S Mukherjee honorary lecturer, learning disability psychiatry

S Hollins professor, learning disability psychiatry

Mohammed T Abou-Saleh reader, addictive behaviour

Department of Mental Health, St George's Hospital Medical School, London SW17 ORE (rmukherj@sghms.ac.uk)

Jeremy Turk reader, developmental psychiatry

Department of Clinical Developmental Sciences

Competing interests: None declared.

1 Jones KL, Smith DW. Recognition of the fetal alcohol syndrome in early pregnancy. Lancet 1973;2:999-1001.

2 Lemoine P, Harouseau H, Borteryu JT, Menuet JC. Les enfants des parents alcooliques; anomalies observees apropos de 127 cas. Oeust Medical 1968;21:476-82

3 Burd L, Martsolf JT, Klug MG, Kerbeshian J. Diagnosis of FAS: a comparison of the 4-digit diagnostic code: the Institute of Medicine criteria and the fetal alcohol syndrome diagnostic checklist score. Neurotoxicol Teratol 2003;25:719-24.

4 Jacobson JL, Jacobson SW. Effects of prenatal alcohol exposure on child development. Alcohol Res Health 2002;26:282-6.

5 Famy C, Streissguth AP, Unis AS. Mental illness in adults with fetal alcoFamy C, Streissguth AP, Unis AS. Mental illness in adults with fetal a
hol syndrome or fetal alcohol effects. Am J Psychiatry 1998;155:552-4.

6 Riley EP, Guerri C, Calhoun F, Charness ME, Faroud TM, Li TK, et al. Prenatal alcohol exposure: advancing knowledge through international collaborations. Alcohol Clin Exper Res 2003;27:118-35.

7 Ikonomidou C, Bittigau P, Ishimaru MJ, Wozniak DF, Koch C, Genz K, et al. Science 2000;287:1056-60.

8 Charness ME, Safran RM, Perides G. Ethanol inhibits neural cell-cell adhesion. J Biol Chemistry 1994;269:9304-9.

9 Sood B, Delaney-Black V, Covington C, Nordstrom-Klee B, Ager J, Templin T, et al. Prenatal alcohol exposure and childhood behaviour at age 6-7 years: dose response effect. Paediatrics 2001;108:e34-5.

10 Knupfer G. Abstaining for foetal health: the fiction that even light drinking is dangerous. BrJ Addict 1991;86:1063-73.

ing is dangerous. $B r J$ Addict 1991;86:1063-73.
11 Kaskutas LA, Graves K. Pre-pregnancy drinking: how drink size affects Kaskutas LA, Graves K. Pre-pregnancy drin
risk assessment. Addiction 2001;96:1199-209.

\title{
Neglected diseases
}

\section{"Priority medicines for Europe and the world" is a wake up call from WHO}

$\mathrm{F}$ ew readers of the $B M J$ were probably aware or even cared that the presidency of the EU Council was held by the Dutch government during the second six months of 2004. Nevertheless, history is likely to remember the Dutch presidency with gratitude. For in the run up to it, the Dutch government commissioned the World Health Organization to develop a research agenda for the European Union that was based on public health needs for priority medicines.

The commendable report was published last November. ${ }^{1}$ Masterminded by Warren Kaplan and Richard Laing, and using a new approach, it is a work of scholarship. It covers a wide range of critical issues and makes many far reaching research proposals for the European Union. But underlying these extensive data and careful analyses are some chilling implications. Here are a few.

Firstly, contemporary notions of neglected diseases are far too circumscribed. They include both rare (orphan) diseases as well as common disorders (mainly communicable) of developing countries. But the neglected diseases also include a range of other conditions that are major burdens in all countries and for which we have few or no effective remedies. Epidemic influenza, appearing annually, probably causes a million deaths a year worldwide. But pandemic influenza, appearing every few decades, has much more devastating consequences. The pandemic of 
1918-9, for example, killed an estimated 40-50 million people. Research into influenza, in relation to its catastrophic potential, is underfunded. ${ }^{2}$ Worse still, we do not even seem able to provide sufficient vaccine to control epidemic influenza in the most developed countries. Little confidence exists that we could undertake a global immunisation programme for an influenza pandemic even if we had sufficient warning of its antigenic profile unless we can sharpen up on manufacture and distribution. Other notable examples of neglected diseases afflicting the world include antibacterial drug resistance, chronic obstructive pulmonary disease, alcoholic liver disease, and stroke. ${ }^{1}$

Secondly, the pharmaceutical industry is clearly unable to meet the needs of people with neglected diseases. This is not a criticism but a fact, for the pharmaceutical industry is a business and needs to provide its shareholders with a return on their investment. Many neglected diseases are unlikely to to do this and investment represents a great commercial risk. The industry will continue to play a major part in the discovery and development of drugs; but we need much greater pluralism in both the funding and discovery of novel treatments.

Examples of this pluralistic approach already exist. Substantial public funds for basic and clinical research, ultimately aimed at producing new forms of treatment, are available in the United States and to a lesser extent in Europe. The research agenda in the WHO report should be a major feature of the European Union's next research programme. For this we must rely on the influence of the Dutch presidency. But Europe also needs to harness the potential of public-private partnerships along the lines of the Global Alliance for TB Drug Development, or the Hereditary Disease Foundation in the United States. ${ }^{3}$ Public-private partnerships involve joint investment of resources by bodies including universities, government supported research organisations, pharmaceutical companies, venture capitalists, and research based charities. The Hereditary Disease Foundation's public-private partnerships include, for example, not only the foundation itself but several pharmaceutical companies and academic researchers of the Huntington Study Group collectively seeking an effective treatment for Huntington's disease; and that of the Global Alliance for TB Drug Development is a joint initiative between the Rockefeller Foundation, the Bill and Melinda Gates Foundation, $\mathrm{WHO}$, a group of university based investigators, and several private companies. ${ }^{3}$

Thirdly, the cost of developing a new drug must be reduced. ${ }^{4}$ Unless savage cuts can be made in the current cost of bringing a new drug to the market-over $\$ 800 \mathrm{~m}(£ 423 \mathrm{~m} ; € 605 \mathrm{~m})$ and rising at the rate of $10 \%$ a year ${ }^{5}-$ drug development will come to a standstill. Half this sum seems to be consumed by clinical development programmes. But real inroads need to be made into reducing all regulatory requirements if affordable new drugs are to be available to consumers. ${ }^{4}$ Promisingly, the problem has been acknowledged by both the US Food and Drug Administration and the European Medicines Agency, ${ }^{67}$ but international action is needed if these difficulties are to be resolved. Radical regulatory reform that is acceptable to the United States, the European Union, and Japan will be essential to relieve our current woes. This will have to include reducing the burdens of preclinical studies and adopting innovative approaches to investigating efficacy and safety in patients. ${ }^{4}$

Finally, the boundaries between primary and secondary prevention of disease clearly need to be redrawn. The silos currently occupied on the one hand by public health specialists and on the other by clinicians must be eroded. Prevention and control of disease need to go hand in hand. The transfer of the public health functions of the Health Development Agency to the National Institute for Clinical Excellence (NICE) as of April 2005 offers a real opportunity for this to happen-at least in England. ${ }^{8}$

\section{Michael D Rawlins professor}

Wolfson Unit of Clinical Pharmacology, Medical School, University of Newcastle, Newcastle upon Tyne NE2 4HH

(m.d.rawlins@ncl.ac.uk)

Competing interests: MR has been chairman of NICE since its formation in 1999

Kaplan W, Laing R. Priority medicines for Europe and the world. Geneva: World Health Organization, 2004. http://mednet3.who.int/prioritymeds report/index.htm (accessed 5 Nov 2004).

Treanor J. Weathering the influenza vaccine crisis. N Engl J Med 2004; $351 \cdot 2037-40$.

3 Moses H, Braunwald E, Martin JB, Their SO. Collaborating with industry-choices for the academic medical centre. $N$ Engl J Med 2002; industry-choi $1371-5$.

4 Rawlins MD. Cutting the cost of drug development. Nature Rev Drug Discov 2004;3:360-4.

5 DiMasi JA, Hansen RW, Grabowski HG. The price of innovation: new estimates of drug development costs.J Health Econ 2003;22:151-85.

6 European Medicines Agency. The European Medicines Agency road map to 2010: preparing the ground for the future. London: European Agency for the Evaluation of Medicinal Products, 2004

7 Food and Drugs Administration. Challenge and opportunity on the critical path to new medical products. Department of Health and Human Services: path to nedical pou html (accessed 6th Nov).

Department of Health. Report on the reconfiguration of the Departmen of Health's arm's length bodies. London: Department of Health, 2004 www.dh.gov.uk/PublicationsAndStatistics/Publications/Publication PolicyAndGuidance/PublicationsPolicyAndGuidanceArticle/fs/ en?CONTENT_ID = 4086081\&chk=y4UIfP (accessed 6 Nov 2004).

\section{The treatment of lupus nephritis}

\section{New and more conservative approaches in treatment are a major advance}

$\mathrm{F}$ or 30 years the US National Institutes of Health have dominated the treatment of lupus nephritis with controlled trials of monthly high dose intravenous pulse cyclophosphamide, now the standard treatment for nephritis and severe lupus. However, adverse effects such as ovarian failure and infections are significant with prolonged treatment. ${ }^{1}$ As most lupus patients are women of childbearing age, this price has been high and patients and clinicians are questioning this protocol. Recent studies offer two different approaches that may be as effective and better tolerated.

Additional references w1-w4 are on bmj.com 